\title{
Review of the Research on Energy Consumption Evaluation Index System of Campus
}

\author{
Han Ying ${ }^{*}$, Han Jianqiang, Xu Guoqiang, Liu Shikuan and Cui Jing
}

\author{
Earthquake Engineering Research Center of Hebei Province, Hebei United University, Tangshan, 063009, China
}

\begin{abstract}
In recent years, with the fast development of economy and technology, people's living standards have gradually improved, which lead people to consume the energy excessively. Especially As the large flow of people and system complexity, the university campus occupied a large proportion in the energy consumption. Currently, the school admissions showed a rising trend and the population is highly concentrated. Therefore, the construction of the campus enter into a peak period.Tthe scale of the campus is expanding, and more and more energy is consumed. To solve these issues, it starts from the campus energy-saving and energy-consuming to establish an effective evaluation system of energy consumption. On one hand, it could be understood that $d$ the overall situation of building energy consumption easily, on the other hand, it can detect the movements of the different aspects of building energy consumption, in order to facilitate the further development of campus building energy in the future work. It is reviewed the research status of the campus energy consumption evaluation index system at home and abroad, and proposes some future prospects on constructing green campus in the article.
\end{abstract}

Keywords: Campus, energy consumption, evaluation index system.

\section{INTRODUCTION}

Green campus concept was first proposed at the United Nations Human Environment Conference in Stockholm. in 1972, the environmental education ideas embodied in the conference is the source of the green schools ideas. In 1994, UNESCO proposed the "education for sustainability", it was the integration of environmental education and development education, population education, etc, and turned environmental education for sustainable development. In 1997, UNESCO meeting in Greece, determined the "education for sustainability" concept and formed the "education for sustainable development." The emergence of educational thought for sustainable development promoted the development of "green school" theory. In 2007, the United States launched the "Coalition of University Presidents deal with Climate," and announced the university campus will be into a "carbon neutral" zone. Early June 2009, "the International Alliance for Sustainable Campus" conference held in Switzerland, the excellent schools that selected out from more than 30 of the world's renowned universities and research institutions was awarded the international sustainable school award.

\section{EXISITING APPROACHES}

\subsection{AEC Index}

AEC is year-round air-conditioning power consumption index per unit area, it is based on the actual power

*Address correspondence to this author at the Earthquake Engineering Research Center of Hebei Province, Hebei United University, 46 Xinhua West Street, Tangshan 063009, China; Tel: 13832882759;

E-mail: hanying@tju.edu.cn consumption survey data, obtained by fitting the power consumption and related factors in relation, including the area and heat transfer coefficient of windows and walls, installed capacity and operation mode of air pumps, the heat dissipation of indoor personnel, the temperature setting of indoor [1].

\subsection{Energy Intensity Index}

Energy intensity index is the total energy per unit area of the building, it can be used as an indicator of energy consumption evaluation, but it is difficult to determine the energy use and energy saving potential with a single value [2].

Filippm used the school energy consumption data and the building area of central Argentina to calculate its energy intensity index, and put the calculated energy intensity index finishing into a reference table [3]. Simple construction area of energy intensity indicators can be used to beam energy performance of commercial buildings, Singapore's energy efficiency benchmarking system, Birtles and Grigg used a similar approach. However, Monts and Blissett discusses the commercial buildings that the limitations of the single normalized energy intensity index, some factors may be the cause of special building energy consumption is higher than general types of building energy consumption.

\subsection{IPLV}

Integrated part load value of water chiller unit or unit formula units (IPLV) the concept of integrated part load efficiency originated in the United States, in 1986 began to use, in 1988 was used by the U.S. Air Conditioning and Refrigeration Institute,1992 and 1998 has been amended 
twice. All America's major chiller manufacturers through the 1998 version of IPLV, when calculated IPLV we should not first converted energy efficiency ratio of standards specified operating point to EER under four points.

Umberto Desideri, Stefania, Proietti analyzed the energy of a school building in Italy [4], by calculating the main thermal indicators and indicators to determine the energy consumption situation, and energy-saving renovation for it. Among them, heat, electricity index is the annual per cubic meter heat consumption and power consumption of each student or each class.

Shi-Ming Deng, John Burnett investigated the energy consumption of 16 hotel buildings in Hong Kong and used EUI as energy index [5].

Caglar, Selcuk, Canbay, etc. used the Performance Index, the annual energy consumption per unit area to evaluate the building energy of a shopping center [6].

\section{RESEARCH STATUS OF CAMPUS ENERGY CONSUMPTION}

\subsection{Developed Countries}

With the proposed of green campus concept, countries all over the world have put the idea of sustainable development into the school education, the famous universities abroad active in low-carbon campus building activities. At present, there have been nearly 4000 universities to applied for and received the certification of LEED.

There are more than 4,000 colleges and universities around the United States, and approximately 19.6 million college students. According to the annual report released by the U.S. Energy Information Administration showed that U.S. campus energy consumption continued to rise. The survey found that in the campus energy consumption, lighting energy consumption accounts for $31 \%$, heating accounts for $28 \%$. To this end, the American University had carried out energy-saving actions taken various measures to build university campus into a green campus with period features. For example, Yale launched since 2005 to reduce greenhouse gas emissions by $10 \%$, in two years time, reduce greenhouse gas emissions by $17 \%$ and reduce electricity consumption of college dormitory by $10 \%$. Harvard freshmen need to accept green guidance before enrollment. Massachusetts Institute of Technology set aside $\$ 3,000,000$ for the development of energy-saving measures annually from 2005 to 2009, focusing on energy-saving lamps refurbished, steam system updates, the optimization of heating and ventilation and air conditioning systems. The college has also established a revolving fund of $\$ 2,000,000$ for funding research and development of energy efficiency, through the use of mature technology saving energy, and the money saved can be used to other campus for the development of energy saving. University of California, Berkeley, have developed their own carbon reduction targets: Plan in 2014 to restore the greenhouse gas emissions to 1990 levels, by 2050 carbon emission levels had a $80 \%$ lower than 1990 [7]. Therefore, Berkeley school district has adopted a series of measures to reduce carbon emissions. In the specific implementation process, the school focused on improving energy efficiency and developing renewable energy. Establish a low-carbon campus executive team, release and change information timely; establish a comprehensive information management systems and classroom lighting systems; according the temperature to regulate heating and cooling inside the building; at the same time also actively looking for alternative sources of energy. The school also by advocating closed laboratory fume hood readily when we not needed; after using the computer monitor off these tiny details promptly, such as to reduce carbon emissions.

There are 13,000 students and faculty members in Tokyo University, consume a large part of the energy, annually consumed about $136000 \mathrm{t}$ carbon dioxide emissions. So the school formulated two objectives to reduce carbon dioxide emissions: by 2012 carbon dioxide levels achieved a 15\% reduction compared to 2006; 2030 carbon dioxide levels lower than 2006 by $50 \%$. The School in order to achieve the emission reduction target for a variety of carbon dioxide emission sources were evaluated, and connecting with the actual situation formulate the optimal principles of the construction of low carbon campus - The Campus carbon dioxide emissions to a minimum, reduce the maintenance cost of the entire life cycle. In order to achieve the 2012 carbon dioxide emission targets, the University of Tokyo implemented the following specific measures: (l) Install visual power meter to control the expansion of research and teaching activities caused by carbon dioxide emissions increase; (2) support the modernization and replacement of energy-saving equipment; (3) import and popularize development model based on large-scale purchasing energy saving device ; (4) continue to study and find other ways to save costs.

University of Nottingham Jubilee Laguna Campus school building make full use of natural light to reduce artificial lighting to achieve energy saving effect. The main teaching building internal of Jubilee Laguna Campus are installed in a passive infrared motion detector and sunlight sensors, and be controlled by intelligent lighting central system unified: When someone in the classroom, the system will automatically determine whether to use the lighting system, which replaces the manual switch; if there is enough natural light indoors, lighting system will automatically shut down, thus saving energy. In addition, the British University of East Anglia in the process of building a low-carbon campus, and always adhere to raise the teachers' and students' awareness of energy conservation, establishes the low carbon concept in the first place, through taking publicity measures to guide the teachers and students actively participate in energy conservation action, forming a culture of energy conservation.

\subsection{China}

In recent years, the state has increased investment in higher education, education has developed rapidly. Currently, the number of Chinese universities has reached more than 3,000, the total number of students at the school has more than 30 million people, according to incomplete statistics, student on campus student energy consumption, water consumption were more than urban residents' average. Huge number of campus buildings, energy demand is growing rapidly, the country's total energy consumption on 
campus accounts for the proportion of total social energy consumption is gradually increased. High school in the process of construction and development, according with relevant provisions of state promulgated the "public building energy efficiency design standards," "Energy conservation management," will shift construction of the campus from the traditional high consumption development model to the high ecological development model. In 2007, under the organization of State Department of Housing and UrbanRural Development, China's first campus-saving demonstration project started in Tongji University, from this driving the creation and development of a large number of conservation-oriented campus, in joint promotion of State Ministry of Housing, the Ministry of Education and Finance, elected to the national campus-saving demonstration has more than 200 institutions, of which more than 20 colleges and universities campus energy efficiency supervision system construction through the national acceptance, has made important achievements and experience, and received highly education at home and abroad. Ministry of Education is also issued a "Ministry of Education on the school to carry out saving emission reduction action notice" on September 20, 2007, which emphasizes the promotion of environmental awareness and training students, and encourage students to actively carry out social practice energy conservation.

Beijing University of Technology investigated the first teaching building of the school found that the heating energy consumption of air conditioning in the building energy consumption accounts for more than $52.3 \%$, the school in addition to air conditioning energy consumption, lighting and other office appliances also occupy a large proportion, the current phase focused on energy conservation in air conditioning, ventilation and heating energy consumption. Through the analysis of the main building there are two aspects: First, the air-conditioning system uses a drag multi section air-conditioning, managing distributed, leading air conditioning in the running state for a long time, a serious waste of energy. Second, lack air conditioning, lighting distribution energy management system. To this end, the school had taken the following measures: (1) increased computer-controlled management system of central air conditioning and power distribution energy efficiency; (2) air conditioning and lighting systems increased monitoring and control system; (3) set up the network controller, realize the time-sharing, partition control of lighting system on each floor. At present, the hot topic of study of Beijing University of Technology in the aspect of water saving is comprehensive development and utilization technology that extracted heat from domestic wastewater. The drainage temperature of school bathroom is relatively high, hot water bath, wastewater temperature is still able to reach about $30^{\circ} \mathrm{C}$, heat recovery potential is very large. Comprehensive treatment by water treatment technology, after reaching the required standards, part of the hot water make use of heat pump technology for building heating, another part of hot water may be used for dormitory toilet flushing by heat pump low-temperature backwater, reach comprehensive development and utilization of domestic wastewater purpose [8].
Researchers investigated and studied the Peking University found that: how to reduce the energy consumption is the key problem to the sustainable development of Peking University. Therefore, Peking University from the perspective of energy conservation, had taken a series of reform measures to the internal campus. For example, implemented a series of management programs: "Interim Measures for Electricity of Peking University", "Interim Measures for Water Conservation of Peking University", "Interim Measures for the Administration of Peking Utilities" and so on, water and electricity take charge of the quota management and metering way for schools to save a lot of water and electricity costs. In addition, Peking University realized the automatic control of all the selfprepare well in technology; all school buildings were installed ceramic core faucet; campus green space adopt the technology of water-saving irrigation; constructed water systems in the dormitory; transformed the single steel windows in the campus to reduce heat dissipation of indoor; focus on promoting energy conservation, established the concept of energy efficiency of staff and students and so on. These actions of Peking University lead the various low carbon constructions among domestic university campus.

Tongji University has achieved some success in energy efficiency on campus, it is the first to perform the technology of low-carbon. The school comprehensively considered the characteristics of large space conditions of the school building as well as its conditions of use and natural conditions, explored the technology of natural ventilation, preheating and pre-cooling technology of fresh air conditioning, ground air technology, passive and active building energy efficiency technologies, through transformation of energy conservation, integrated energysaving ratio exceeding $65 \%$. In addition, the school in order to ensure the sustainable use of resources, established a large of wetlands alongside the river to reach filtration and purification of sewage. Tongji University also combined their multidisciplinary strengths, ongoing low-carbon technology innovation. In June 2010, Tongji University built the green low carbon "solar bamboo house", bamboo house integrates a number of building energy saving technologies and energy saving systems, efficient used and managed the energy electricity and thermal what needed for daily life. In addition, the pattern of the compound not only can facilitate ventilation cooling, but also can improve the micro climate of the outdoor environment.

Fudan University through the effect of personal behavior on energy consumption and individual energy conservation and emissions that meet the characteristics of Fudan campus to explore and analysis the construction of low-carbon campus [9]. Through the results relevant questionnaires and analysis, the energy consumption management level of functionality of the campus building is low, on the basis, the school put forward construction management system of low carbon campus, effectively implemented energy conservation and emissions reduction in the whole campus, and established a low-carbon campus. It has been proved that low input or even zero-cost investment to improve the 
management and promote behavioral change more often than mere technical means of high investment can make more effective and immediate contribution in energy saving.

\section{CONCLUSION}

Although at present there are more and more campus energy consumption evaluation index systems and methods in our country. However, it still needs a large number of research to improve a more complete and scientific evaluation index system.

(1) Strengthening the use of new energy sources. Schools can make full use of solar to transform hot water heating system, recovery the heat of exhaust gas positively, in terms of improving temperature of the indoor to take a more ground source heat pump engineering, while thermal insulation for the outer layer of building carrying out to energy saving measures, improving the efficiency of energy saving.

(2) Using energy-saving materials and technologies. Schools should actively introduce energy-saving equipment and technology, take advantage of the school itself to research high-tech energy-saving technologies and products, it can not only save energy, reduce energy consumption on campus, but also can save a large part of money for school.

(3) Increasing the publicity efforts, improving awareness of energy conservation of all the teachers and students. Propaganda and education of university should take the concept of saving throughout the teachers' and students' learning, working and life, as well as we should joint the student union organization, actively organize to carry out the energy conservation as the main content of the practice, in this way let people gradually learn energy conservation.

(4) Establishing effective management and evaluation systems of campus building. We should learn lessons from foreign successful architecture evaluation system, such as the "Green Building Rating System" that been established and implemented by the U.S. Green Building Council, referred LEED internationally, setting up effective management mechanism and the quantitative evaluation system in accordance with China's national conditions. At the same time, energy management department of universities should make the principle of energy saving implement to infrastructure projects of each school, but also accord on energy standards to issue indicators for each departments of schools, inspire the enthusiasm of energy efficiency incentives across each sectors and individuals.

Establishing energy regulation system on campus. It should be adopted the energy-saving regulation system on the campus collected indicators in real time and remotely monitor for waters, electricity, gas and other kinds of energy consumption data and indicator in each building, the unreasonable energy usage should be eliminated.

\section{CONFLICT OF INTEREST}

Financial contributions to the work being reported should be clearly acknowledged, as should any potential conflict of interest.

\section{ACKNOWLEDGEMENTS}

This paper belongs to the project of the "Hebei Province Department of Education Excellent Youth Fund", No. YQ201406.

The authors acknowledge the valuable comments made and provided by the anonymous reviewers in the early version of this manuscript.

\section{REFERENCES}

[1] Lee, W.L.; Yik, F.W.H. Regulatory and voluntary approaches for enhancing energy efficiencies of euildings in Hong Kong. App. Energ., 2002, 71, 251-274.

[2] Chung, W.; Huia, Y.V.; Lamb, Y.M. Benchmarking the energy efficiency of commercial buildings. App. Energ., 2006, 83, 1-14.

[3] Filipp, N.C. Benchmarking the energy efficiency and greenhousegases emissions of school buildings in central Argentina. Build. Environm., 2000, 35, 407-410.

[4] Desidesi, U.; Proietti, S. Analysis of energy consumption in the high schools of a province in central Italy. Energ. Build., 2002, 34, 1003-1016.

[5] Deng, S.M.; Burnett, J.A. Study of performance of hotel buildings in-Hong Kong. Energ. Build., 2000, 31, 7-12.

[6] Canbaya, C.S.; Hepbaslib, A.; Gokcenc, G. Evaluating performance indices of a shopping centre and implementing HVAC control principle to minimize energy usage. Energ. Build., 2004, 36, 587-598.

[7] Guo, Y. F. Create a green campus, practice the low carbon life Inner. Mongolia. Sci. Tech. Economy, 2012, 1, 28-29.

[8] Liu, T.X. The application and understanding of concept of energy saving and environmental protection campus construction. China. Build. Waterproof., 2010, 10, 97-99.

[9] Zhang, Y. The Application of Energy saving and environmental protection campus construction. Cooperat. Econ. Sci., 2013, 14, 469. 